\title{
LA MÚSICA EN LOS SALONES DEL OVIEDO DECIMONÓNICO: EL MUNDO SALONIER EN LA CIUDAD DE CLARÍN
}

\author{
MUSIC IN OVIEDO NINETEENTH CENTURY'S ROOMS: \\ THE SALONIER WORLD IN CLARIN'S TOWN
}

\author{
$\mathbf{M}^{\mathrm{a}}$ Aurelia Díez Huerga \\ Universidad de Oviedo
}

\begin{abstract}
Resumen
Durante el siglo XIX tiene lugar una práctica social muy apreciada en los hogares europeos, costumbre que prolifera en las ciudades españolas, entre ellas Oviedo. Herencia dieciochesca, es un modo de socializar consistente en la reunión periódica de amigos o vecinos para pasar un rato agradable. Lo que había comenzado en forma de tertulias desenfadadas y sin pretensiones en residencias particulares, pierde con los años su naturalidad, dando lugar a un ceremonial encorsetado y asfixiado por las formas protocolarias, sobre todo en los sectores sociales más elevados. Las fuentes hemerográficas testimonian una intensa vida de salón en Oviedo, la Vetusta clariniana, registrando una importante actividad musical en los domicilios de las principales familias. Sin perder su valor como expresión artística, la música asume un relevante papel como elemento dinamizador en tales espacios, gestándose un repertorio con rasgos propios, todo lo cual intentaremos reflejar.
\end{abstract}

\section{Palabras clave}

Sociabilidad informal; Tertulia; Soirée; Círculos; Música de salón; Diletante; Piano; Clarín; Bailes.

Las costumbres de salón forman parte de los rasgos identificativos históricamente atribuidos a la sociedad europea del siglo XIX. Con sus tópicos y caracteres, los salones privados asumen un papel esencial como espacios recreativos en los ámbitos aristocrático y burgués de esta centuria, ya que las necesidades disipativas de las familias pudientes no alcanzan su plena satisfacción en los encuentros organizados por las entidades recreativas del momento -recordemos que las clases medias-altas son las únicas que tienen acceso al ocio organizado, proporcionado en liceos, ateneos

\begin{abstract}
During the nineteenth century a social practice takes place, very estimated in European homes, a custom that expands in Spanish towns, Oviedo among them. A heritage from the eighteenth century, it's a way of socializing that consists of periodical parties for friends or neighbours to have a good time together. What had started as free and unpretentious social gatherings in private homes loses progressively its naturalness, giving rise to a strict ceremony, suffocated by formal ways, most of all among upper classes. The journalistic sources give evidence of an intense salonier life in Oviedo, Clarin's Vetusta, registering an important musical activity within the main families' dwellings. Without losing its value as artistic expression, music takes on a significant role as an energizing element in those spaces, while a new repertory with genuine features is developing, all that we'll try to reveal here.
\end{abstract}

\section{Key Words \\ Informal sociability; Social gathering; Soirée; Societies; Sa-} lonier music; Dilettant; Piano; Clarín; Balls.

y círculos, al disponer de tiempo libre y medios económicos para cubrir los gastos de suscripción-. En el Oviedo decimonónico, lo mismo que en Madrid, cuyo modelo las ciudades de provincias toman como referencia, hay insignes personalidades que abren sus puertas a grupos de amigos con los que compartir una agradable velada nocturna. Tales reuniones o soirées, en las que la música toma parte, proliferan de modo especial a partir de los años cincuenta, siendo referidas en las crónicas de la época con el mismo detalle que las fiestas en las sociedades recreativas. 
"Como yo, conoces las agradables reuniones que tienen lugar en las principales casas de la población, en que se hacen los honores a las encantadoras musas de Euterpe y Terpsícore, y en que lucen su habilidad y gracia niñas, que sin ser musas, no por eso tienen menos encantos.

El jueves último estuvo brillante como nunca, la sociedad de la señora de V., que recibió a sus constantes amigos con su acostumbrada amabilidad y finura [...].

El domingo cantó por primera vez en casa de C., la señorita doña R. A.; en la linda canción de La cola del diablo, reveló una voz agradable y simpática, y espero que, desechando temores, vayan dándose a conocer así las habilidades de otras niñas"1.

Así pues, "la vida social de antaño, más íntima y acogedora, no carecía de alicientes que cooperaban a suplir la falta de espectáculos públicos con cotillones o conciertos en el Casino y asaltos de lo más florido de nuestra juventud a alguna mansión señorial, donde los hospitalarios moradores se deshacían en agasajos a la simpática hueste asaltante y se improvisaban animadas fiestas que al día siguiente tenían su resonancia periodística en los brillantes ecos de sociedad" 2 . Naturalmente, hay reuniones para todos los gustos y, según la circunstancia y el ánimo de los anfitriones, las veladas adoptan un tono más o menos confidente, más o menos ceremonioso o rimbombante. El modo más informal, muy arraigado en Oviedo, es la tradicional y casera tertulia del atardecer. De variada tipología, el ciudadano desocupado puede elegir la que más se acomoda a sus apetencias en virtud de la plática y de los asistentes habituales a cada una.

“Así, por ejemplo, una encopetada señora muy piadosa, que vivía sola en su sombrío palacio, tenía su tertulia desde el toque de la oración, pero de clérigos solamente. A las nueve en punto se despedían indefectiblemente las sotanas. Otra dama, de análogo rango social, aunque más mundana, reunía en torno suyo a la élite de la sociedad femenina ovetense de su mayor intimidad, hablándose entre ellas, como es corriente, de trapos, de noviazgos, de proyectos de boda o del estado decadente del servicio doméstico, mientras su opulento esposo, abrigado con talma de color gris, cerrada al cuello con broche de oro, no lejos de la chimenea donde chisporroteaban trozos de leña, formaba grupo aparte con sus contertulios, que jugaban al tresillo o trataban de cuestiones de politiquería local"'.

1 BUSTILLO (1890): 344.

2 SEÑAS ENCINAS (1949): 38.

3 SEÑAS ENCINAS (1953): 20.
No hay que olvidar las reuniones con fines matrimoniales que, como en Madrid, proliferan entre las solteras ${ }^{4}$. De un modo u otro, las veladas en los salones cumplen una innegable función social y son especialmente necesarias como espacio recreativo para los jóvenes, alternativa a círculos, teatros y cafés ${ }^{5}$.

De vez en cuando la reunión de amigos deja de ser una sencilla tertulia, adquiriendo mayores dimensiones. Las invitaciones se extienden a conocidos y otras amistades menos íntimas, celebrándose en ellas conciertos y bailes en los que los jóvenes se deslizan por el salón al compás de valses y rigodones.

Desde un punto de vista sociológico y en todas sus variantes, el salón de la Vetusta clariniana, espacio retratado en La Regenta, desempeña una clara función de enlace entre los miembros de una misma clase social, especialmente el aristocrático y el burgués, ámbito selecto donde se tratan asuntos políticos y se ajustan negocios, se murmura del prójimo y se conciertan matrimonios. La entrada en ciertos salones conlleva la aceptación, la pertenencia al grupo. Por contra, la exclusión significa la marginación social. De la apertura o cierre de tal o cual puerta derivará la facilidad o dificultad para sortear obstáculos en el futuro ${ }^{6}$. Entrar en los principales salones de la ciudad significa tener influencias, razón por la cual son tan concurridos, entre otras causas.

La costumbre de salón aparece estrechamente vinculada a otra que, si bien se practica en diferente franja horaria, no carece de formalidades. Hablamos de las visitas, ritual complementario de las tertulias y de obligado cumplimiento entre los ovetenses de buena posición. Para las visitas se reserva lo mejor y más selecto de cada hogar, algo más perceptible en la clase media que en la aristocracia.

"En toda casa de burguesía que se preciara se les dedicaba la muy posiblemente mejor habitación de la casa: la sala de las visitas, a la que estaba rigurosamente prohibido entrar a nadie y, sobre todo, a los niños. En ella se encontraban los muebles más valiosos de la casa: consolas isabelinas de mármoles y espejos de dorado marco, sillerías de caoba, mecedoras de aire ultramarino, espesos cortinones de Damasco. Los adornos mejores tenían en ella su museo: el reloj traído de Londres o

4 SEÑAS ENCINAS (1953): 21. El autor menciona las tertulias organizadas periódicamente por unas ancianas solteronas, quienes abren sus puertas a pollos de uno y otro sexo para entablar amistad.

5 CASIELLES (1961).

6 FERNÁNDEZ GARCÍA (2000): 174. La lectura de esta magna obra de Clarín nos conduce por las vicisitudes de Ana Ozores, víctima precisamente de la maledicencia que envenena las conversaciones de salón. 
París, el objeto oriental del tío de Cuba o Filipinas, que podían llegar incluso a formar una vitrina que hoy valdrá un platal. Y presidiendo casi siempre los retratos de los antepasados, de los dueños o de algún joven desaparecido en plena mocedad. La obra pictórica solía correr a cargo de algún artista local, especializado en estos pingües menesteres. Y cuando no se llegaba al pincel, suplía la gran fotografía iluminada"7.

Al igual que sucede en los encuentros vespertinos de salón, las visitas acostumbran hacerse siguiendo un protocolo. Son las mujeres de la familia las que habitualmente reciben, salvo en ocasiones excepcionales. En los domicilios de abolengo hay incluso días establecidos para tales recepciones, algunas de las cuales se dan a conocer por medio de la prensa. Los temas y los gestos a los que se recurre en ellas, incluso los tiempos, se ajustan a unos cánones.

"Era un lenguaje hecho de lugares comunes, donde la salud y el tiempo se llevaban buena parte, con incursiones a las labores femeninas, incluida la repostería. En las visitas todo estaba muy reglamentado: las mujeres no se sentaban cómodamente, dando a entender la brevedad del encuentro. Pues bien, la conversación adolecía de esta falta de confianza, que impedía, asimismo, el ofrecimiento de cualquier golosina o bebida, como no fuera algún azucarillo, tan fatal para los diabéticos, enfermedad fin de siglo" $"$

Por otra parte, hay determinadas circunstancias en las que una visita resulta del todo inexcusable. No felicitar el Año Nuevo, las Pascuas, el nacimiento de un niño, por ejemplo, no transmitir las condolencias en un acontecimiento luctuoso - pésame- o hacerlo con retraso sería considerado un descuido imperdonable, derivando en la ruptura de relaciones con la familia ofensora. Todo esto nos da idea de la mentalidad decimonónica, caracterizada por el cultivo de relaciones humanas imbuidas de una susceptibilidad asfixiante, la cual ha ido relajándose en épocas posteriores.

Volviendo a la actividad salonesca, entre los testimonios más antiguos conservados en Oviedo se halla la crónica de una soirée organizada a mediados de los sesenta para el público infantil. Es una muestra de la traslación que ciertos hábitos adultos realizan hacia el mundo de la infancia, algo que también ocurre en las sociedades recreativas con los bailes de disfraces.

7 GARCÍA DE CASTRO (1979). 8 GARCÍA DE CASTRO (1979).
"Soirée de niños. Anteayer tuvo lugar en casa de los señores marqueses de Gastañaga y Deleitosa la segunda reunión de pitinos y pitinas que llenaban en esa noche las espaciosas salas que se les habían destinado. La inocencia y el candor, que parece se esconden, y cual si se avergonzasen de vivir entre nosotros, con dificultad se presentan en esta clase de sociedades, tenían allí su asiento, puesto que la función se celebraba exclusivamente en obsequio de los niños. La murmuración, la mentira, la hipocresía social, que no deja nunca ver las cosas como son en sí, no fueron admitidas en aquel recinto, donde solo imperaban la buena educación, la verdad y la envidiable sencillez de los que aún no han cumplido tres lustros. ¡Edad dorada, de inestimable valor, cuyo recuerdo excita la seriedad del jóven más risueño y hace asomar las lágrimas de los ancianos!

Todo concurría a enaltecer el cuadro y darle colorido. Cuando entraban las niñas en el salón, solo se cuidaban de dirigirse al sofá ocupado por la señora marquesa, y a su lado la que sin haber dejado de ser su hija, lo es hoy también de los señores marqueses del Real Transporte. Los saludos, que concluían con esos estallidos que llaman besos, y cuyos ecos llegan a conmover en ocasiones al hombre, aunque sepa toda la filosofía de Aristóteles y sea más retraído que quien convirtiera en ermita la casa del Renegado, hacían el acompañamiento del piano que tocaban asimismo dos niños, de los cuales solo hemos conocido al de la rizosa cabellera que corrió por el teclado como un maestro; y este título llegará a merecer con el tiempo el interesante Adolfo.

Terpsícore, de suyo tan bulliciosa, se vuelve frenética cuando anda entre los niños. Una danza tras otra, ahora un rigodón, después schotiss, acto continuo wals, no se daba mano a las piruetas y a los saltos; y desde las ocho a las diez y media no se concedieron más treguas al baile, ni se le dejaba por nada de este mundo, sino para saludar y aún acariciar con la mayor ternura las bandejas de plata, que coronadas de finos y variados dulces a cada paso se servían. Quisiéramos saber los nombres de tantos ángeles como aquel cielo llenaban [...] (9 Diciembre 1864)"9.

Es de suponer que las prácticas de salón permanecen inalterables durante los años sucesivos, pues no se conservan noticias al respecto hasta finales de los setenta, época en que la familia Aldanese organiza conciertos y bailes en su domicilio. Brigadier de profesión, el señor Aldanese congrega a lo más granado de la sociedad ovetense en esplendorosas fiestas, alternativa a las del Casino y el Liceo -las sociedades recreativas más pujantes a la sazón- en momen-

9 GONZÁLEZ SOLÍS Y CABAL (1889); 461. 
tos de especial escasez en lo que a diversiones públicas se refiere. Con motivo de celebraciones familiares o en fiestas señaladas -Navidad, Pascua, tampoco faltan los conciertos sacros en Cuaresma- estos animosos anfitriones organizan veladas en torno a la música, protagonista indiscutible, que a menudo comparte espacio con la poesía. Entretenidas y variadas sesiones para un público ávido de pasatiempos, sustentadas en la desinteresada colaboración de aficionados, muchos de los cuales también frecuentan los círculos del momento.

"Un concierto.- Sres. Redactores de los Ecos del Nalón: Mis queridos amigos: he prometido dar a Vds. cuenta de aquella fiesta de carácter íntimo y tengo la inverosímil costumbre de no faltar nunca a mi palabra.

Había empezado la saison, y en espera de las reuniones del Casino, la buena sociedad distraíase entre los palcos del Teatro y las sillas del Skatin-ring, recordando con pena las agradables soirées que en el pasado invierno les habían proporcionado grato solaz en torno del piano que domina con tan exquisito gusto una distinguida señora.

Por fin, el día de la Concepción, y para celebrar los días de su simpática hija, el Sr. Brigadier Aldanese reunió a sus amigos en una de aquellas veladas de feliz recordación para los que tienen el gusto de tratar a su amable familia. Se trataba de un concierto; y un concierto dirigido por una artista como la Sra. de Aldanese presenta siempre alguna novedad y encantador atractivo.

Empezó la fiesta con una bonita romanza que cantó la señora Concha Casanova, con su preciosa voz de contralto y con la gracia que ella sabe dar a lo que canta. La señora de la casa y nuestro amigo Eugenio Labán, cantaron después un dúo de barítono y soprano de Los dos Fóscaris; y después se formaron los coros, en el fondo del gabinete donde está el piano, para cantar el Miserere de El Trovador. Figuraban en los coros de tiples y contraltos las señoritas [...]. De Manrique y del coro de hombres, no les digo a ustedes nada, pero no me parecería galante olvidar la ajustada ejecucion, el colorido, la precision con que desempeñaron su cometido las bellas coristas; al oírlas hubiera uno querido que la fiesta fuese al término [...].

Terminado el concierto y reunidos ya los cantantes a la elegante concurrencia que escuchaba en la sala, se bailó un rato, se pasó luego al buffet, para tornar en seguida al baile.

Concluyo, amigos míos: no me atrevo a emprender la tarea de apuntar los nombres de las familias que asistieron a la fiesta de aquella noche; pudiera olvidar alguno y esto me traería serios disgustos. Pero, al concluir, quiero participar a ustedes que, según mis noticias, tendremos otra velada igual el día de Navidad, es decir, un motivo o una ocasión más para agradecer la amabilidad de la distinguida familia Aldanese.

Saluda a Vds. cordialmente su afectísimo amigo q. b. s. m.

$$
\text { Valerio" }{ }^{10} \text {. }
$$

Una vez más todo son alabanzas para los artistas, sin duda merecedores del respeto y la admiración de sus espectadores. A pesar de ello, los críticos no son tan conformistas como parece. Un escueto artículo publicado por esas fechas en la Revista de Asturias nos ofrece otra perspectiva, lanzando, en brevísimas líneas, un dardo envenenado al diletantismo imperante. Contiene una entusiasta exhortación al público ovetense para asistir a las funciones que la nueva compañía de zarzuela programa en el deteriorado teatro municipal, elogiando a los empresarios que se aventuran a alquilar nuestro avejentado coliseo. De no ser así, estos huirán $\mathrm{y}$
"dónde echaremos entonces esas kilométricas noches del invierno? ¿Son tantos los que se quedan en casa para recibir amigos y amigas y hacer los honores de sus salones con aquella amabilidad que caracteriza siempre a los recibidores? ¿Dónde iremos á hacer música? Nos entregaremos al inocente teatro casero, donde hay una docena de Herodes artísticos para cada producción dramática. ¡Ah... nó! Meditemos... [...] Sin zarzuela en el Fontán estamos perdidos, completamente perdidos"11.

En los primeros años ochenta se detecta una intensa actividad de salón. A comienzos de la década se estilan los bailes en domicilios privados y en salas acondicionadas al efecto por ciertas corporaciones sin ánimo de lucro o por hábiles empresarios que aprovechan la ocasión de hacer un buen negocio. Ejemplo del primer caso lo constituyen las soirées que desde hace mucho tiempo se organizan anualmente en el cuartel de Santa Clara para celebrar la Navidad, a las que acude una escogida concurrencia, entre ella señoritas casaderas entusiasmadas por el encuentro con apuestos militares. Nuevamente, al ritmo de valses, mazurcas, rigodones, lanceros y otros bailes foráneos en boga, la ocasión para el cortejo está servida.

"Las fiestas de Navidad. 1816-1881. [...] La escogida reunión que allí se hallaba sobresaliendo como era natural, pollas elegantes y hermosas, militares obsequiosos,

10 Ecos del Nalón. Oviedo, I/5 (15.12.1877): 39-40.

11 Revista de Asturias. Oviedo, II/36 (25.10.1878): 477. 
estudiantes animados, música en el cuartel y en el salón de Academia adornado con elegancia, claro es que todo esto debía inspirar la necesidad de otra cosa que se oía en todos los ángulos, no en alta voz: «¿No habrá baile?».

Y el baile se improvisó, siendo como era natural que la Sra. Coronela hiciese los honores de la casa. Mi madre, aunque de carácter un poco circunspecto, daba a entender perfectamente el agrado que sentía cuando alguno de los jóvenes sacaba a bailar á mi hermana, la que estaba altamente satisfecha, porque, como se dice ahora, ni una sola vez había comido pavo.

No habían penetrado en España las novedades introducidas años después por los amantes de Terpsícore. Los rigodones y lanceros, las mazurcas y cotillones no se conocían y solo sí estaban en boga entonces los airosos wals y complicadas contradanzas españolas [...]"12.

Gran aceptación, por otro lado, tienen los bailes que el empresario Matías Azpiri comienza a ofrecer en sus salones de la calle Campomanes. Por módico precio, damas y caballeros tienen acceso a baile, aseo y refacción, todo con el máximo orden y un servicio impecable. Se trata de una extrapolación de los bailes que por entonces programan centros recreativos como el Casino al ámbito de la sociabilidad informal, donde se emula su organización y se persigue el glamour alcanzado en aquellos, galanteo amoroso incluido, mas sin el aparato estatutario que los envuelve.

"El baile, que con buen acuerdo, se empieza ahora a las cinco de la tarde, porque es sabido que los días están de medro, y ya anoche cerca de las seis, estuvo animadísimo.

No hay que dudar que Matías tiene vena de empresario. El salón bien barrido, regado, limpio... Los mozos con gorro «autorizado», con aquel caprichoso apéndice en el centro de la parte superior que tanto se asemeja a un acento.

Se baila con la debida compostura, cosa que no eché nunca de menos.

Detalles del baile.

En el salón, muchas «comían pavo» a desgana.

En el ambigú se tiraba a los vencejos, a los glayos y a toda la caza mayor... sin perder tiro.

\section{RECTA"13}

El espectáculo alcanza su cenit durante las populares fechas de la Candelaria y Carnaval, rivalizando en esplendor

12 El Carbayón. Oviedo, III/140 (20.01.1881).

13 El Carbayón. Oviedo, V/594 (16.01.1883). con las fiestas celebradas en residencias particulares y círculos. Incluso se establecen varios turnos de baile, en horas tempranas o avanzadas, posibilitando mayor acceso de público. Con tales facilidades horarias, un servicio de atención al cliente completo - la entrada incluye tocador para las señoras, selecto ambigú y ropero surtido con una amplia selección de disfraces- y un interesante repertorio de bailables, en ocasiones interpretado por la banda municipal, el éxito está garantizado.

"En los salones de Campomanes habrá dos grandes bailes de máscaras el día de la Candelera.

La hora de entrada del primero será desde las cuatro de la tarde hasta las ocho. El segundo, desde las diez de la noche hasta las cuatro de la madrugada.

Los salones estarán caprichosamente decorados. El tocador estará a cargo de los Peluqueros Sres. Prado y García, donde encontrará el público toda clase de disfraces.

Para estos días tiene ensayados nuevos y muy bonitos bailables la acreditada banda de música de «Santa Cecilia».

El ambigú estará tan bien surtido como el mejor para esta clase de espectáculos"14.

Los bailes de pago proliferan en estos años, consolidando una modalidad de ocio muy rentable. Es frecuente la diversificación de los precios para varones y mujeres. Las damas, consideradas protagonistas de los encuentros, entran por menos dinero. Es una forma de garantizarse una holgada afluencia, dado que tras las féminas vienen los pollos, y con ellos la sala se llena. Con similares características a las de Azpiri se organizan fiestas en las dependencias de la antigua Escuela de Párvulos en los días de San Mateo, por ejemplo, o para recaudar fondos en beneficio de la cofradía de la Balesquida. Posteriormente se abrirán al público las dependencias en su día ocupadas por la Sociedad Juventud Mercantil al objeto de ofrecer espectáculos flamencos, de forma paralela a lo que sucede por entonces en algunos cafés de la ciudad.

Centrándonos ahora en los salones particulares, hemos de citar el de la familia Masaveu, apellido insigne en Oviedo. El poderoso financiero Pedro Masaveu es un popular anfitrión que en bailes de Carnaval y reuniones de confianza congrega a las más distinguidas familias ovetenses.

14 El Carbayón. Oviedo, V/607 (01.02.1883). Observemos los horarios de las fiestas, la hora de cierre tan tardía en el caso de la segunda. Si pensamos en el Liceo, por ejemplo, es sabido que algunas veladas remataban a las seis de la mañana. Así pues, los hábitos trasnochadores de la población actual son algo heredado de bien atrás. 
"En la noche del domingo tuvimos el gusto de concurrir a la reunion que con el carácter de confianza dio el Sr. D. Pedro Masaveu.

Sus grandes salones se hallaban llenísimos de bien vestidas máscaras que discurrieron agradablemente por espacio de dos horas entre los muchos grupos que allí se formaron.

La estudiantina de León también se lució ante aquel gran concurso y todos bailaron y se divirtieron mucho, pasando después al comedor donde servidos por las bellísimas hijas del Sr. Masaveu fueron obsequiados con champagne, otros vinos y delicadas pastas todos los allí reunidos.

Mil gracias al Sr. Masaveu y otras tantas felicitaciones a su amable señora y bellísimas hijas que tambien supieron cumplir en ocasion tan especial como es la de un baile de máscaras" 15 .

Las fiestas de Carnaval son igualmente muy celebradas en casa de D. Medardo Álvarez, calle Campomanes, y en la de los señores de Cutre, familia asturiana de abolengo.

Los bailes de máscaras, delirio de los adultos, que en los centros recreativos tienen su modalidad infantil, continúan por esa línea. Siempre hay una familia de buena posición que abre sus puertas a un desfile de chiquillos entusiasmados, los cuales recorren las salas llenándolas de color con abigarrados disfraces, ante la complacida mirada de sus progenitores.

La mayor actividad en los salones aristocráticos y burgueses de Oviedo se detecta a mediados de los ochenta. Las familias más selectas de la ciudad se congregan al anochecer, entre las nueve y las diez, en alguna residencia para bailar, escuchar música, representar teatro, hacer juegos, recitar poemas, tomar delicatessen y conversar hasta la madrugada. Tarea perfecta para los desocupados. Al igual que sucede en los centros recreativos, la temporada de los salones comienza en los meses de octubre o noviembre -tras el letargo estival, tiempo de playas y balnearios- y se prolonga hasta junio, siendo interrumpida durante la Cuaresma, con algunas excepciones. Por esos años, la agenda de un asiduo concurrente a las soirées está repleta de compromisos, pues en ciertas semanas los encuentros son diarios. Cada familia tiene establecido un día para su recepción, algo consabido en determinados círculos, dándolo incluso a conocer por medio de la prensa, como sucede también con las visitas.

"Señor Director: Siempre ha llamado la atencion de que en la capital asturiana hubiese pocos medios de pasar agradablemente las largas veladas del invierno. Estos medios, a falta de espectáculos públicos, eran las reuniones. Comprendiendo esto, se empezaron a abrir en octubre y noviembre algunos salones, donde se reunían los íntimos de las amables familias que proporcionaban esas horas de placer, a la juventud sedienta ya de solaz y de recreo. Pero en la última semana, fue tal la animación y se fue generalizando tanto, que hubo días de estar reunidos tarde y noche, y en distinta casa. Esto viene a demostrar una vez más el axioma de «querer es poder,» y de que, habiendo una iniciativa, no faltan nuca elementos de distracción y entretenimiento.

Hagamos ahora, si bien ligeramente, una reseña de las reuniones celebradas últimamente. Los lunes, como saben los lectores de EL CARBAYON por las cartas de María, son los días destinados por los Sres. Álvarez Taladrid para recibir en sus elegantes salones donde se reune lo mas selecto de high-life ovetense. El martes recibió la Sra. Doña Amalia Díaz Pedregal de Díaz, habiendo salido todos los concurrentes altamente reconocidos de la amabilidad de la señora de la casa y de sus bellísimas hijas. El miércoles se abrieron nuevamente los salones de los Sres. Álvarez Taladrid y los de otras varias casas, celebrándose el fin de año, echando los estrechos, en los cuales hubo de todo; esperanzas de salir con su «amada o amado,» y realidades demostrando lo contrario. Con este motivo eran de ver al día siguiente todas las confiterias inundadas de alegres y simpáticos jóvenes, que iban en busca del cucurucho para su estrecho, y por cierto que hubo magníficos regalos, siendo algunos un tanto significativos.

El jueves por la tarde se reunió la crème de nuestra sociedad en los espaciosos salones del distinguido Brigadier gobernador militar Sr. Labarra, por ser los días de su bella hija Manuela. Inútil será el decir, que hubo luego un espléndido refresco, haciendo los Sres. Labarra e hijas los honores con aquella benevolencia que les es tan característica.

Por la noche, y como de costumbre, se hizo música entre los íntimos del señor Casado, gobernador civil de la provincia, siendo obsequiados con un delicado thé.

El viernes nos vimos privados de la reunión que suele improvisar en su casa nuestro amigo el Sr. Ochoa, a causa de una reciente desgracia de familia, de que tuvo noticia ese mismo día. Por último, los sábados recibe la elegante

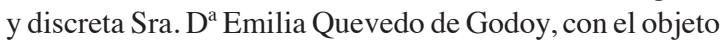
exclusivo de hacer música, aunque de vez en cuando se deslice algun rigodon o se hagan juegos de prendas.

Ya ve V., querido Director, lo que Oviedo promete en el invierno. Lo que ahora conviene es que continúe así [...].

Adiós, señor Director, y dándole las gracias anticipadas por la inserción de estas líneas, le dará cuenta de otras veladas, su affmo. ,

Oviedo 4 de Enero de 1885" ${ }^{\text {Norma }}$.


Cualquier ocasión es buena para convocar a los amigos. No faltan las fiestas en días señalados como Navidad, Pascua, Reyes, Año Nuevo y, sin duda las más esplendorosas, Carnaval. A esas se añaden las celebraciones de aniversarios, onomásticas y cumpleaños, los días de..., como suelen aparecen en las crónicas. Las más célebres en esta época, y también las más frecuentes, tienen lugar en la residencia de D. Joaquín Álvarez Taladrid, Presidente de la Audiencia o Regente ${ }^{17}$. Sito en la calle Cimadevilla, el hermoso edificio del XVII -originalmente destinado a Palacio de la Audiencia y más tarde a vivienda del Regente-, abre todos los lunes sus puertas a una escogida congregación de damas y caballeros que, ataviados con sus mejores galas, se adentran en los magníficos salones, ávidos de diversión. Son los lunes de la presidencia, así denominados en los ambientes de la buena sociedad. Reuniones de confianza, bailes de etiqueta y de máscaras, conciertos, funciones dramático-musicales, veladas interminables que hacen perder la noción del tiempo entre risas, evocadoras melodías, miradas seductoras y exquisitos licores.

\section{"Señor Director de EL CARBAYÓN}

Amigo Director: Es proverbial ya en Oviedo la galantería y amable trato de los Sres. Álvarez Taladrid.

Pocas semanas pasan sin que proporcionen a la buena sociedad ovetense, ocasión de disfrutar las delicias de una reunión de confianza, o de un baile de trajes, o de un brillante concierto.

Los Sres. Álvarez Taladrid y sus bellas y simpáticas hijas, dejarán entre nosotros gratísimos recuerdos, si algún día llegan a abandonar esta capital, en donde cuentan muchas y muy buenas amistades $[\ldots]$.

Serían las nueve y media de la noche y ya los elegantes y espaciosos salones de la casa de los Sres. Álvarez Taladrid se hallaban invadidos por lo más escogido de la juventud ovetense [...]. Los pollos eran muy finos y muy galantes; eran muchos y muy simpáticos. Renuncio a citar los nombres por temor a herir susceptibilidades [...].

Después de bailar un rigodón, en el que tomaron parte no menos de diez y seis parejas, principió el cotillon.

La Reina del baile, Victoria Taladrid, estaba encantadora y presidió la fiesta con verdadera majestad.

Únase a esto la acertada distribución del Cotillón y podrán los lectores formarse una pálida idea de la brillantez del espectáculo [...].

17 Ricardo Casielles, en el capítulo VIII de su serie "La cultura musical de Oviedo", publicada en La Voz de Asturias a lo largo de 1961, menciona las reuniones en casa de D. Fermín Cruz, en la calle del Sol, y las de los Sres. Cabines, en la calle Oscura, como anteriores a las de la Regencia. Sin embargo, no hemos encontrado alusiones a tales encuentros en las fuentes hemerográficas consultadas.
Y ya comprenderá V., señor director, que la fiesta debe haber resultado muy brillante, cuando yo, que soy mujer, la aplaudo de todas veras al reseñarla, porque es sabido que las mujeres no encontramos nada bien [...]"18.

De todas las diversiones halladas en los salones de la Presidencia, las más esperadas, las más deseadas por los jóvenes son los bailes de Carnaval, los cuales se viven con verdadero éxtasis. Tanto es así que la prensa los anuncia con semanas de antelación, informando periódicamente sobre los preparativos que las atareadas muchachas de buena posición van realizando con vistas a tal acontecimiento -trajes, tocados y complementos-. Basta leer las crónicas de $E l$ Carbayón para tomar conciencia de la trascendencia de estas fiestas, auténtico acontecimiento social. Realmente prolijas, a veces ocupan varias columnas en una inagotable retahíla de nombres y descripciones de trajes, mayormente femeninos. Si los bailes extranjeros privan entre el público a la sazón, comienzan a ponerse de moda ciertas danzas, también foráneas, rescatadas del pasado. Tal es el caso de cotillones y minués, de tradición dieciochesca, o de la pavana favorita de Luis XIV, que los jóvenes ensayan ahora con entusiasmo para escenificar en las soirées, enfundados en trajes de época.

"Una gran parte de la juventud ovetense, está preocupada estos días preparando los disfraces para el baile de trajes que en el próximo Carnaval habrá en los salones del Sr. Presidente de la Audiencia.

Parece que todas las señoritas llevarán disfraces, como asimismo todos los pollos, porque se ha impuesto esta condicion a los que habitualmente asisten a los salones de la Presidencia.

La fiesta promete ser brillantísima, y si no fuera porque se nos ha exigido la mayor reserva, describiríamos algunos de los trajes que seguramente lucirán más en esa noche tan esperada. Sólo nos atrevemos a hacer pública una de las novedades que la soirée ofrecerá: se bailarán dos minués, uno de ellos dirigido por una bella señorita, y otro por un pollo discípulo de Galeno; las parejas vestirán trajes de fin del siglo pasado.

$\mathrm{Si}$ podemos hacerlo sin ser indiscretos, aún publicaremos algunos detalles de la soirée antes que ésta se realice" 19 .

Los bailes de época hacen furor en estos momentos, atestando las salas del palacio de la Audiencia. El éxito de

18 El Carbayón. Oviedo, VI/979 (29.04.1884).

19 El Carbayón. Oviedo, VII/1200 (26.01.1885). 
las fiestas induce a los anfitriones en 1885 a realizar una ampliación en el edificio para dar cabida a tamaña afluencia. El cierre del palacio desviará temporalmente la concurrencia a otros domicilios también muy visitados, reanudando poco después su marcha con la misma intensidad. La esplendidez de la señora Álvarez Taladrid se pone de manifiesto asimismo en las fiestas infantiles o bailes de piñata que organiza por Carnaval. Entre aquella chiquillería estrepitosa y alborozada que inunda los salones desde horas tempranas de la tarde encontramos las primeras referencias a uno de los músicos asturianos más valorados en las décadas subsiguientes. Infante todavía, Baldomero Fernández hace sus pinitos en el piano ejecutando piezas de baile que sus compañeros siguen con movimientos acompasados, temprana muestra de sus aptitudes para el arte musical.

"El domingo último se verificó en el salón de los Sres. Álvarez Taladrid el baile de Piñata a que concurrieron muchos niños, luciendo vistosos trajes, cuyos vivos colores y variados estilos formaban un abigarrado y encantador conjunto.

Vestían: Maria Álvarez Taladrid, de preciosa ridícula; Ángeles Cañedo Longoria, de bohemia; Pura Fierros, de incroyable; Ángeles Polo, de locura; Manolita Canella, de zíngara [...].

Las piezas de baile las ejecutó al piano con mucha soltura y precision, el niño Baldomero Fernandez, y bailó algunos bailes andaluces Lolita Molina con inimitable gracia.

El baile terminó a las diez de la noche y los niños, fueron todo el tiempo atendidos con su acostumbrada amabilidad por la Sra. de Álvarez Taladrid, que los obsequió con cucuruchos de dulces" ${ }^{20}$.

20 El Carbayón. Oviedo, VII/1224 (24.02.1885). Baldomero Fernández Casielles (1871-1934), músico ovetense de extraordinario talento, es uno de los artistas asturianos que pudo haber desarrollado una brillante carrera internacional pero las circunstancias de la vida truncaron ese feliz proyecto. La muerte de su padre cuando aún era un estudiante prometedor le impidió continuar su formación en el extranjero, obligándole a permanecer en Oviedo y desempeñar trabajos de pocas aspiraciones - profesor particular, pianista de café, entre otros- para sacar adelante a su familia. En palabras de Benito Álvarez Buylla, "pudo haber sido el músico asturiano, pero fue pobre y tuvo que ganar el pan cotidiano saciando la codicia de los empresarios de teatros y cines que exigían demasiado por muy poco dinero. Y necesitó también para malvivir adular a la bambolla burguesa, desasnando muchachos a quienes sus progenitores daban por futuros astros del piano. Y así, entre aquella tarea destructora y esta ingrata labor docente, se fue diluyendo el optimismo del quizá más inspirado y fácil de nuestros compositores” [GARCIA MIÑOR (1978)]. Artista ecléctico, aparte de la música cultivó la literatura y la pintura, si bien con menor intensidad. Sobre B. Fernández véase URÍA LÍBANO (1997).
Pasado el delirio de los Carnavales, el recogimiento y la austeridad se imponen como actitudes propias del tiempo cuaresmal. La mayoría de los salones detiene su actividad en estas semanas, en consonancia con el sentimiento religioso imperante. No ocurre así con el palacio de la Presidencia, donde, procurando no contravenir la costumbre, se programan conciertos sacros al estilo de los del Liceo, con la diferencia de que el repertorio es mayormente religioso en este caso. Por lo demás, los conciertos cuaresmales conservan el tono jovial de las veladas ordinarias, si bien se omiten los bailes finales que acostumbran rematar aquellas, tan esperados por el elemento joven.

"El viernes último asistimos al concierto sacro que se celebró en casa de los Sres. de Álvarez Taladrid.

Las Srtas. de Medina y Díaz de Cutre, ejecutaron hábilmente al piano la Marcha de El Profeta y la Srta. de González (María) cantó sentidamente la melodía dulce y sencilla del Ave María de Schubert; la fantasía María de Herold encontró acertada la interpretación en la flauta y el piano por los Sres. Cuesta y Ochoa; la Sra. de Godoy lució su bella escuela de canto y los coros su afinacion y perfecto ajuste en La Caridad de Rossini y en la grandiosa estrofa Inflamatus del famoso Stabat Mater de aquel maestro.

Figuraban en el coro las Srtas. de Vega, Campa, Labarra, Terrero, Godoy, Sierra, Camino y López, y los Sres. de Somoza, Guerrero, Serrano, Flórez, Sarandeses, Terrero, Pumarino, Sierra, Fontela y Prida; y por cierto que llamaba la atencion la unidad y el concierto de la masa coral, que parecia dirigida por un hábil maestro. El coral para piano La Caridad, nos agradó, mas que por su mérito, por la maestria con que lo ejecutó la Srta. de G. de la Fuente (Concha). La Srta. de Cuesta Olay cantó con acertado colorido el Ave Maria de Vellani; y la Srta. de Somoza dijo con delicados matices la célebre aria de Stradella Pietá, Signore, y venció con su gusto y su hermoso estilo las dificultades de la preciosa Ave María de Gounod que acompañaron muy bien la Srta. De Camino (Matilde) en el piano, y los Sres. Ochoa y Bellmunt en el armonium y violín [...].

El buen gusto con que fueron elegidas todas estas piezas de música religiosa, merece ser notado y damos a los inteligentes aficionados nuestra enhorabuena. La señora y las señoritas de Álvarez Taladrid contribuyeron con su amabilidad y sus finas atenciones a hacer más agradable aún la velada"21.

21 El Carbayón. Oviedo, VII/1252 (30.03.1885). 
Terminada la Cuaresma, regresa la actividad en lo que a distracciones se refiere, intensificada ahora por las celebraciones pascuales. Bailes, funciones dramáticas y veladas musicales en la Presidencia son nuevamente anunciados en los diarios, para regocijo de muchos. Huelga decir que en todos los casos el peso recae sobre aficionados, común denominador de las soirées ovetenses. Es práctica muy difundida que las anfitrionas compartan atril con sus invitados o, en menor medida, con algún profesional que asiste a las reuniones, caso del pianista Ramón Ochoa, premio nacional del Conservatorio de Madrid, muy conocido en Oviedo, o del violinista Francisco Torres, colaborador en las sociedades musicales. Los salones constituyen el espacio idóneo para la ostentación de las virtudes femeninas con fines matrimoniales, ocasión aprovechada por las señoritas de la casa y sus amigas a través de la práctica instrumental y el canto. La joven casadera, aprendiz de piano, instrumento preferido por las damas y que ahora se convierte en el rey absoluto de toda fiesta nocturna, se consagra como prototipo de artista aficionado omnipresente en los salones aristocrático-burgueses. No faltan los detractores de esta imagen por considerarla una degradación de la mujer, a quien distrae de sus debidas ocupaciones, y un fraude para los futuros esposos, algo en lo que la música y las noches de salón tienen mucho que ver.

"A ellas.

Allá va un remedio eficaz para encontrar marido. Tener más sentido comun y menos coquetería.

Más ocupaciones útiles y menos música.

Escudriñar mejor los misterios de la casa y menos los cuentos de salón.

Repasar las camisas y las medias y no hacer monadas.

Leer la cocina casera y abandonar los periódicos de modas.

No sacar a relucir trajes que espanten los bolsillos de los candidatos al matrimonio.

Menos balcón o ventana y más costura.

Menos palique y más juicio.

Probar a los hombres que encontrarán una buena esposa y no un mueble de lujo o un estorbo.

Ser, en fin, modesta, virtuosa y... esto es bastante"22.

22 El Occidente de Asturias. Cangas de Tineo, V/ 354 (15.01.1886). La fiebre del piano adquiere tal magnitud que llega a convertirse en una verdadera molestia para muchos vecinos, quienes, hartos de las insoportables cantinelas de los estudiantes a horas intempestivas de la noche, elevan protestas al Ayuntamiento para que tome medidas al respecto. El alcalde ordena a los serenos que reprendan a los que molesten con sus ensayos pasadas las diez de la noche, algo que no surtirá los efectos deseados. Véase CASIELLES (1961).
No obstante, la labor de los aficionados en términos generales es muy valorada en las crónicas, que ordinariamente ensalzan sus cualidades interpretativas. Ignoramos el grado de objetividad vertido en las críticas y, por tanto, su credibilidad, pero dejan constancia del aprecio mayoritario que la figura del artista diletante suscita en nuestra ciudad, a diferencia de lo que sucede en Madrid, donde las opiniones al respecto son más controvertidas.

Nuestro paseo por los salones ovetenses nos conduce ahora a la residencia del Gobernador Militar, ubicada en el antiguo convento de Santa Clara. Aquí el brigadier Sr. Labarra celebra bailes por Carnaval, recibiendo a los mismos invitados que frecuentan el palacio de la Audiencia. Felices desocupados van de fiesta en fiesta, en un deleite continuo de música y alborozo que dura hasta la madrugada.

"Si D" Maria de Llanes y Avilés, abadesa y restauradora allá por los años de 1751, hubiese vuelto por sobrehumano poder a los claustros del convento de Santa Clara en las primeras horas del domingo, ella y sus compañeras de reclusión hubieran retrocedido asustadas ante la deslumbradora visión de caballeros y damas, moras y arlequines, diablos y pastoras que en bullicioso tropel asaltaban su tranquila morada, juzgándolos seguramente como representación de las vanidades mundanas allí enviados por el genio del mal para tentación de sus recogidos espíritus. No era ésa, por cierto, la intención de la alegre multitud que, en vistoso y abigarrado conjunto, invadía los salones del Gobierno Militar, en donde les brindaba algunas horas de grato solaz la amable cortesía de los Sres. de Labarra.

Como la gran mayoría de la concurrencia era la misma que en la noche anterior llenaba los salones de la Presidencia, nos ocuparemos principalmente en reseñar las personas que asistieron solo a esta segunda fiesta; dando a la vez breve noticia de los nuevos trajes que en esta noche se lucieron.

Como bases generales, apuntaremos que las toilettes de señoras revistieron el carácter de severa elegancia y riqueza que en la noche del sábado habiamos admirado; que se lucieron con ligeras excepciones los vistosos trajes anteriormente descritos, y que nuevamente, en los minuetos de Mozart y Arrieta, volvimos a admirar las variadas figuras que con mesurado y grave compás reproducían las diestras parejas [...].

$\mathrm{Si}$ este (el baile) ha tenido lugar con estraordinaria brillantez; si todos pasamos en él agradables horas, agradezcámoslo a las bondadosas atenciones de los Sres. de Labarra, que abriendo de par en par casa, adornándola con esquisito gusto y afanándose por complacer a sus numerosos amigos, se han hecho una vez mas acreedores a las muchas simpatias que tan amable familia goza en Oviedo. 
Eran próximamente las dos de la madrugada cuando abandonamos, no sin pesar, tan amena reunión y ¿es posible (dirán muchos y muchas) que de tantas emociones, placeres y alegrías, no quede nada dentro de algunas horas? [...].

$$
\text { JUBILADO",23. }
$$

Los viernes recibe el Gobernador Civil de la provincia, Sr. Casado. Las veladas musicales, prolongadas y eclécticas, se inician con la interpretación de obras vocales e instrumentales y cierran con un baile, haciendo una pausa en torno a la media noche para tomar un refrigerio, generalmente a base de exquisitos dulces acompañados de té y licores. En aquellas amenas reuniones de la familia Casado, junto a los consabidos diletantes, se hacen oír también jóvenes promesas, músicos locales que comienzan a abrirse camino en el mundo artístico y gozan ya de cierto reconocimiento fuera de la provincia. Hablamos del pianista Ramón Ochoa, antes mencionado, y del violinista Antonio Bordas, ambos premiados por el Conservatorio de Madrid. Así pues, el salón decimonónico constituye, de igual modo que las sociedades musicales, un espacio abierto a la proyección de músicos noveles, que tienen vedado el acceso a otros escenarios, como el teatro, por lo general más accesibles a profesionales ya consagrados.

\section{"Sr. Director de EL CARBAYÓN.}

Muy señor mío. El viernes fue el día señalado en la semana pasada por los Sres. de Casado para recibir según costumbre a sus numerosos amigos; el señor Alau, que reside hace unos días entre nosotros, tuvo la buena ocurrencia de presentar al joven Sr. Bordas, de quien con tanta justicia como competencia se ha ocupado V. en su ilustrado periódico, llamándole un verdadero genio; denominación que acepto, después de oírle ejecutar a la altura de un Sarasate o Fortuni, los números de Souvenir de Haydn, Concierto de Beriot, Adios a la Alhambra, y otros en los que consiguió arrebatarnos, porque su violín canta, ríe o llora, según quiere el Sr. Bordas; siga ese camino y luego su nombre honrará nuestra patria, aumentándose el prestigio que en esto nos distingue la actualidad, figurando con los Monasterio, Sarasate, Gayarre, etc. etc. La circunstancia de asistir los Sres. Ochoa y Blanchart a tan amena velada fueron causa de que resultara un concierto que me atrevo a calificar de brillante, puesto que rara vez pueden reunirse en esta capital dos premios del Conservatorio Nacional, como son Bordas y Ochoa, éste, como siempre, maestro y

23 El Carbayón. Oviedo, VII/1217 (16.02.1885). original en las piezas que ejecuta al piano, entre las que recuerdo un nocturno sorprendente, acompañando al distinguido y simpático artista Sr. Blanchart, que con su armoniosa y sonora voz cantó Non é ver y Non torno, haciendo las delicias de los concurrentes; no sería justo si al contar de la noche no expidiera el título de profesoras a Luisita Casado y María González, que fueron aplaudidas al ejecutar, a cuatro manos, la Sinfonía de Semiramis; y conste que la emulación en el arte ayuda al genio, y es muy de apreciar que midieran sus fuerzas con los ya reputados: María cantó con su dulcísima voz y con el sentimiento de su hermoso corazon, Morir per tè.

A las doce fue servido un expléndido thé [...].

A las tres de la mañana abandonamos aquellos salones con verdadera tristeza, pues ciertos momentos jamás debían concluirse, y aún me parece que escucho aquellas incomparables notas y bailo el rigodón con una de las pollas que he citado y que todas rivalizaban en belleza y elegancia.

Cumplo una vez más lo prometido al enterar a V. de lo que aprecio digno de contarse, y se repite siempre suyo.

$$
\text { U de la R" }{ }^{24} \text {. }
$$

Lo mismo sucede con las familias Carrizo y Sierra, en las calles San Francisco y Jovellanos respectivamente. Los Sres. de Sierra reciben los lunes ${ }^{25}$ y, siendo su anfitrión melómano y violinista aficionado, asiduamente abren sus puertas a contertulios dispuestos a gozar de agradables sesiones de interpretación musical. En su casa constatamos la presencia de uno de nuestros prohombres del ochocientos. Figura destacadísima en el ámbito artístico, promotor cultural, pianista, compositor y anfitrión también en su residencia, Anselmo González del Valle toma parte como intérprete en las veladas de Sierra. La música por sí misma adquiere el protagonismo en estas reuniones, pues, a diferencia de lo que sucede en otras salas, el baile aquí nunca tiene lugar.

"Eran las diez de la noche y, asombraos... ¡no llovía! Como el que espera pasar dos o tres horas todo lo felices posible en este mundo donde las contrariedades surgen a cada instante, dirigíame yo a casa de los Sres. de Sierra, sabedor hace ya tiempo de la amabilidad y trato finísimo de estos señores y noticioso, además, de que aquella noche se había dado cita allí lo mejor y mas elegante de la sociedad de Oviedo [...].

24 El Carbayón. Oviedo, VII/1407 (05.10.1885).

25 No es infrecuente que varias familias programen soirées en una misma noche, por lo que a menudo se adelantan o posponen las reuniones para evitar coincidencias. 
Es imposible decir todas las que allí estaban, ¡tantas había! Pero os diré, en cambio, que Conchita de la Fuente ejecutó al piano, con gran perfeccion y maestría, el preludio del Anillo de hierro; tambien cantó, como ella únicamente sabe hacerlo, Asunción López de Polo; después de esto figuraos que cantaron un lindísimo dúo la Sra. de Cuesta y la de Rodríguez Valdés. A Ramón Ochoa, nunca le he oído ejecutar como anoche; todo cuanto en su obsequio dijera sería poco; pero la impresión duraba todavía cuando el Sr. G. del Valle (D. Anselmo) hizo que conservemos para siempre recuerdo de esa noche. ¡Qué admirablemente y con qué sentimiento interpretó dos lindísimas melodias! Después... después de las Srtas. de Argüelles y de las de Merás, cantó la Sra. de Somoza un aria de Lucrecia, y tocaron las Srtas. de la Fuente y la Sra. de Sierra admirablemente al piano. He dejado con intencion a la Sra. Franco de Salas, porque quiero decirle que es una cantante como hay muy pocas, que hay una expresión, una dulzura en las notas que ella dice, como yo no he oído nunca. Ademas leyeron preciosas composiciones [...].

A la una saliamos, y... preguntaréis: ¿y tú amigo F.? Mi amigo salió conmigo y me decía ¡qué bien ha estado todo, hasta las calabazas que me han dado por memo!

$$
\text { A. B. U." }{ }^{26} \text {. }
$$

Pero si hay en la ciudad de Clarín algún lugar donde la música goza de auténtico protagonismo por su valor artístico ese es el palacio de Anselmo González del Valle y Carvajal, en la calle de Toreno. Hijo de un indiano que alcanzó la fortuna en Cuba, de D. Anselmo cabría decir que "pudo ser en su época uno de los primeros pianistas de Europa, en posesión como estaba de todos los recursos técnicos para lograr fama internacional; pero despreció los más fabulosos contratos para anclar definitivamente su vida en la calle de Toreno, prefiriendo la compañía y la tertulia de un grupo de amigos escogidos"27. No hay que olvidar su faceta compositiva, que desarrolla en unas doscientas obras, algunas inspiradas en temas populares asturianos. Esta vena de inspiración folclórica lo sitúa, junto a autores como Baldomero Fernández, Manuel del Fresno, Benjamín Orbón y otros posteriores, en el grupo de promotores del movimiento regionalista en Asturias, enmarcado en el Nacionalismo musical español que despierta en la segunda mitad del XIX ${ }^{28}$. Como consecuen-

26 El Carbayón. Oviedo, VII/1295 (21.05.1885).

27 MARTÍNEZ GARCÍA (1975): 31.

28 URÍA LÍBANO (1995): 231. Sobre la obra de este compositor véase el estudio desarrollado por la misma autora: URÍA LÍBANO (1997). cia de su valía, y en reconocimiento a ella, es nombrado en 1879 académico de la Academia de Bellas Artes de Madrid y, a comienzos de los noventa, Presidente de su homónima en Oviedo, donde funda y dota la cátedra de violín. Ya en el siglo XX, será elegido Presidente Honorífico de la Sociedad Filarmónica, recién constituida ${ }^{29}$.

La familia González del Valle es una de las más distinguidas de la época, impulsora de trascendentes proyectos culturales -no en vano el padre de D. Anselmo fue uno de los protectores de la Universidad ovetense en ciertos difíciles momentos que la institución atravesó durante el $\mathrm{XIX}^{30}$ - y mecenas de compositores asturianos. Su palacio contaba con

\begin{abstract}
"un salón dedicado especialmente a la música en donde se reunían los filarmónicos e intérpretes locales. Aquel salón era un lugar de culto para la música [...] se discutía de música, se estudiaban y ejecutaban versiones de las partituras que llegaban de Europa y se escuchaban diariamente, a primeras horas de las noches, largas sesiones en las que participaban no sólo los compositores locales, sino también algunas grandes estrellas de la música que mantenían relación con el mecenas: entre los extranjeros, destaca Saint-Saëns; otros, españoles de la talla de Tomás Bretón [...]. Y casi todos los que residían en Oviedo, encabezados por Víctor Sáenz, Saturnino del Fresno y Baldomero Fernández" ${ }^{31}$.
\end{abstract}

Estas sesiones, como las de otras residencias, constituyeron la tabla de salvación para la música instrumental de cámara y sinfónica, a través de las transcripciones de obras orquestales para conjuntos más reducidos o para piano solo, cuando esta se hallaba tristemente soslayada en los grandes escenarios. En este punto la labor de Anselmo González del Valle merece especial mención, pues a través de él llegaron a Oviedo numerosas partituras de compositores españoles y europeos, conformando una biblioteca particular con más de 20.000 obras, a lo que hay que añadir una nutrida colección de instrumentos musicales. Como dato anecdótico valga decir que alguno de sus proveedores en el extranjero le consignaba sus pedidos como si de un comerciante se tratara, dado el tamaño de los envíos ${ }^{32}$.

En términos generales, su sabrosa tertulia nocturna atrae a sobresalientes figuras de la esfera cultural, tales como

29 GONZÁLEZ DEL VALLE, José $\mathrm{M}^{\mathrm{a}}$ (nieto del compositor): conferencia pronunciada el 04.03.1980 (documento inédito conservado en el archivo particular de D. Luis Arrones Peón, Oviedo).

30 CONDE (1988): 6.

31 CASAPRIMA COLLERA (1993): 36.

32 CASAPRIMA COLLERA (1993): 36. 
“don Ramón del Busto Valdés, párroco de San Tirso, delicado poeta y humanista de vasta cultura. A don Fermín Canella, con su gran saber y su excepcional gracia de rápidas reacciones. A don Julio Vallaure, hombre de fisonomía aparentemente pícara, tras de la cual se ocultaba un alma de gran bondad. Y don Rogelio Jove Bravo, siempre solemne y atildado [...] que con su mirada penetrante aterrorizaba a sus alumnos de la Universidad [...]. Y don Fernando González Valdés, el prestigioso médico, que quitaba a todo importancia con sus donaires del más puro humor carbayón"33.

Gran animación revisten igualmente los encuentros en las residencias de $\mathrm{D}^{\mathrm{a}}$ Amalia Díaz Pedregal de Díaz y D Emilia de Quevedo y Godoy, estimadas anfitrionas, melómanas e intérpretes aficionadas cuyos nombres aparecen con frecuencia en las revistas de sociedad como voluntariosas colaboradoras en sus reuniones y en las ajenas. Tampoco hay que olvidar a $\mathrm{D}^{\mathrm{a}}$ Luisa de Palacios, viuda de Thiry, quien introduce algunas novedades en sus fiestas de los lunes, como es la intervención de una estudiantina -que da un respiro al piano, protagonista indiscutible en el mundo de salón- o una mascarada, broma jocosa que rompe la dinámica acostumbrada en las noches de soirée. Podemos constatar, de igual modo que en Madrid, la consolidación de la figura femenina como promotora de una intensa actividad de salón en el Oviedo decimonónico, patrona de cenáculos aristocráticoburgueses de gran vitalidad, esenciales en su día para la propagación de ideas, modos y tendencias que imprimieron el carácter de una época.

"La señora viuda de Thiry goza en Oviedo de grandes simpatías y de numerosas relaciones que le dan el cariñoso afecto con que distingue a sus amigos, y la confianza y distincion con que recibe.

Así es que el pasado sábado se vieron los salones de su casa de la calle de Campomanes, y al solo anuncio de que la reunión que acostumbraba a celebrarse los lunes, se adelantaba para ese día, sumamente concurridos y animados.

No se necesitaba para que así fuese la presencia de dos inesperadas visitas; la de una estudiantina, que a primera hora se hizo escuchar en algunas piezas, (entre ellas un hermoso wals primorosamente ejecutado) y la de una numerosa mascarada, que por algunos momentos interrumpió con sus bromas el animado baile a que desde el primer momento se entregaban las muchas y bellas señoritas, y los apuestos y galantes pollos que allí estaban [...].

33 GARCÍA MIÑOR (1976).
Eran muy cerca de las tres de la madrugada, cuando terminó el cotillón, muy bien dirigido por Carmen Rivero y Pedro Valdés, y en el que recibieron tanto las pollas como los pollos lindos regalos, que han de conservar siempre como recuerdo de tan agradable fiesta.

Inútil nos parece decir que la señora de la casa hizo los honores con la distincion y esplendidez en ella habitual" 34 .

La familia del doctor Cuesta Olay también es aficionada a los conciertos privados. Reuniones de carácter depurado, sin bailes ni otras distracciones fuera de la estricta interpretación musical, en ellas intervienen ocasionalmente artistas locales reconocidos. Aparte de Bordas y Ochoa, que por estos años prodigan su arte en los salones, es relevante la colaboración de Rufino Nuevo, profesor de la Escuela de Música y pariente de la anfitriona (cantante y pianista aficionada), y de Saturnino del Fresno ${ }^{35}$, insigne pianista, miembro de una de las familias asturianas de más tradición musical.

"El sábado se verificó en la nueva casa habitacion del conocido médico señor Cuesta Olay una animada reunion musical, en la que la esposa de dicho señor Doña Pilar Nuevo dió á conocer una vez mas su buen gusto y extraordinaria ejecucion en el canto y piano. Ejecutaron tambien selectas piezas musicales el señor Nuevo (D. Rufino), varias aventajadas discípulas y discípulos del mismo, y los señores Ochoa, Vives y Elvira; obteniendo nutridos aplausos de la escojida concurrencia que llenaba la habitacion del concierto y contiguas.

Los concurrentes fueron obsequiado por los dueños de la casa con pastas y licores, quedando sumamente complacidos de la amabilidad de aquellos y de las gratas impresiones de tan animada velada" 36 .

La misma actividad se registra en los domicilios de otros próceres del Oviedo decimonónico, entre los que recordamos al marqués de la Rodriga, el catedrático Enrique Urios, el marqués de Valero de Urría, Rafael Zamora o Juan Uría. Tampoco faltan los músicos que convocan reuniones en sus domicilios. El Sr. Box, destacado maestro de guitarra, da conciertos en los que interviene toda su familia. Los mismos Ochoa y Bordas que ostentan su talento en otras residencias no reniegan del papel de anfitriones, congregando a un grupo

34 El Carbayón. Oviedo, IX/1816 (23.02.1887).

35 Saturnino del Fresno, músico de gran valía, fue pianista acompañante del gran Pablo Sarasate, con el que realizó giras por el extranjero. Pudo haber desarrollado una brillante carrera internacional, pero decidió no abandonar Oviedo, consagrándose a la pedagogía. Sobre este artista véase MARTÍNEZ GARCÍA (1975): 31-32.

36 El Carbayón. Oviedo, VI/1140 (26.11.1884). 
de amigos dispuestos a hacer música. En realidad, muchas son veladas concebidas esencialmente para el lucimiento de los artistas, en las que también toman parte otros colegas del gremio. En este sentido, la familia Bordas destaca por el talento sobresaliente de sus miembros, especialmente Antonio $^{37}$, a quien sus padres exhiben como prodigio del violín en conciertos que muchos admiradores, no pudiendo acceder a la atestada vivienda, escuchan desde las proximidades.

"Anteayer noche tuvimos el gusto de asistir al concierto que el joven y ya notable violinista Sr. Bordas, dio en su casa de la calle de Campomanes.

Desde las primeras horas de la noche se veía esta calle muy concurrida; los aficionados deseaban escuchar una vez mas las delicadas notas que el simpático Bordas arranca a tan difícil instrumento.

El programa era de lo más escogido, y la ejecución fue maravillosa.

El Sétimo concierto, de Beriot; Malagueña y Habanera, de Sarasate; Souvenir de Moscouw [sic], de Wunianwski [sic] ${ }^{38}$; ¿Quién vive! pieza a cuatro manos, ejecutada al piano de un modo notable por Celsa y José, hermanos del jóven violinista; Mazurkas, de Wunianwski [sic]; y El Banjo, difícil pieza tocada con mucha maestría por el pianista Sr. Fresno; fueron escuchadas con religioso silencio, y aplaudidas con entusiasmo, tanto por los que

37 Antonio Bordas, niño prodigio del violín, es otro de los artistas asturianos que no alcanzaron las cumbres que su talento prometía. Quizá la decisión de abandonar la escena musical a temprana edad sea la razón que le relegó al olvido, algo lamentable para Asturias, pues fue elogiado por grandes maestros de su tiempo: "Tendrá ahora D. Antonio Bordas, unos 15 o 16 años, e ingresaba a los diez en el Conservatorio de Madrid, siendo agraciado con el primer premio cuando apenas contaba doce. Grandes dimensiones tendría este artículo si yo tratase de consignar aquí los triunfos obtenidos por este violinista; baste decir que en los ejercicios que periódicamente se verifican en el Conservatorio, tuvieron que ponerle en el último número de los programas, pues una vez que él ejecutaba, ya los demás no podían hacerlo; de tal manera el público se entusiasmaba, que pedía repeticiones, no cansándose nunca de oírle. En una ocasión decía Arrieta, hablando de él, que había empezado por donde deseaban acabar los grandes artistas. Y habiendo oído, otra vez, el gran Sarasate decir que Bordas era una gloria futura de la patria: No -replicó-, es una gloria presente. No hace muchos días he tenido yo el honor de recibir una carta de mi querido amigo D. Enrique Fernandez Arbós, primer premio de los Conservatorios de Madrid, Paris y Bruselas, en la que me dice, entre otras cosas, «Bordas vale más que todos ellos». Pues bien, querido lector; después de todo esto, tú creerás que tan gran artista, no pensará en otro porvenir mas que en el del arte? ¡Pues te equivocas!, le abandona como niño mimado y consentido, ¡por la carrera militar!!!" [El Carbayón. Oviedo, VII/1405 (01.10.1885)]. No obstante, la decisión de realizar otros estudios no implica el abandono de la música, pues varios años más tarde lo veremos de nuevo en los salones dando muestras de su arte.

38 Claramente, se refiere al compositor y violinista polaco Henryk Wieniawski (1835-1880). ocupaban la sala en que el concierto se verificaba, como por el numeroso público que permaneció en la calle hasta muy cerca de la media noche.

Nosotros habíamos leído los justos y merecidos elogios que la prensa de Madrid y de provincias dedicara a tan distinguido artista; pero nos convencimos, después de oírle, de que todo cuanto de él se diga, es poco, si se compara con lo que se merece.

Un jóven que a la edad de quince años ha logrado vencer las incalculables asperezas que ofrece el violín, y que ejecuta como lo hace el Sr. Bordas, más que artista, es un verdadero genio musical.

Si el Sr. Bordas, venciendo escrúpulos, propios de su edad, se dedica exclusivamente al arte musical, será en breve plazo, no solo una gloria nacional, sino europea"39.

También se da el caso de enseñantes particulares que organizan conciertos para dar a conocer los progresos de sus discípulos, a los que asisten familiares y amigos. A menudo, lo que se inicia como un mero concierto de estudiantes en casa de cierto reputado profesor termina adoptando trazas de soirée, improvisada por la intervención de algunos aficionados del público y rematada con el típico baile fin de fiesta, algo que no puede faltar en toda reunión con presencia juvenil. Los conciertos de alumnos son habituales entre el género femenino, al objeto de mostrar los avances efectuados por las señoritas en el arte musical, esencialmente pianístico, una faceta más del estereotipo de la aprendiz de piano que se forja en el XIX.

"CONCIERTO. El sábado tuvimos el gusto de asistir al que la distinguida profesora de piano $\mathrm{D}^{\mathrm{a}}$ Caridad Fernández tenía organizado y que estuvo a la altura de los que acostumbra a dar cada cierto tiempo con objeto de hacer ver los adelantos de sus numerosas discípulas.

A las ocho y media de la noche dio principio ejecutando la niña Amalia Vallés con singular destreza y soltura una fantasía de Marta, logrando arrancar nutridos aplausos; siguió su hermana María con otra fantasía de Sonámbula que en nada desmereció de la anterior; tocaron las dos niñas Manolita y Sofía Acebal, la primera la cavatina del Pirata, de Bellini y la segunda el coro del Crociato, de Meyerbeer, demostrando tanto una como otra un especial gusto en la interpretación de estas obras. Siguieron a estas las señoritas Blanco, San Román y Alegre, que supieron obtener merecidos aplausos en la ejecución de la danza de las Bacantes, Chanson creolle y la Golondrina mensajera $[. .$.$] .$

Alguno hubo también que echó a volar la idea de que habiendo entre nosotros alguna señora que cantaba,

39 El Carbayón. Oviedo, VII/1353 (31.07.1885). 
no debíamos abandonar nuestro puesto sin oírla; y en efecto la Sra. de Cerran de Rodríguez, nos hizo pasar un delicioso rato oyéndola cantar la preciosa romanza «Yo la perdí» recogiendo una buena cosecha de merecidos aplausos.

Aquí creímos, los que ya hemos pasado el Rubicón de la juventud, que terminaría tan agradable reunión, pero nos llevamos chasco. El elemento joven, contra viento y marea, no muy a gusto de las mamás, se propusieron rendir culto a Terpsícore y al fin lograron bailar hasta las doce, a cuya hora se dio la voz de alerta y con gran sentimiento fue abandonada aquella sala donde nos hicieron pasar una noche deliciosa [...].

Réstame, tan solo, enviar a la señora Fernández mis más sinceros plácemes por el brillante resultado del concierto, que demuestra la bondad del método que ha adoptado en la enseñanza y rogarla por último que procure sean mas frecuentes estas reuniones que al par que sirven de poderoso estímulo a sus discípulas proporciona un verdadero placer a los que nos gusta oír buena música.

$$
\text { Pelín" }{ }^{40} \text {. }
$$

Los últimos años ochenta acusan un declive considerable en la actividad de los salones privados, que se acentúa a comienzos de los noventa, cuando apenas localizamos noticias al respecto. Aquellas interminables fiestas en las residencias de las familias más boyantes de Vetusta desaparecen del mapa, quedando algunos restos que, muy de tarde en tarde, jalonan las crónicas de sociedad. En ellos encontramos personajes de la década anterior, inmersos en un rito que no presenta novedades.

"El viernes último se vio sumamente concurrida la casa del Sr. Administrador de correos, D. Darío Blanco, en donde se reunieron las familias de los Sres. Bango, Sierra, Collera, Uría y otras que sentimos no recordar, con el fin de oír al eminente violinista señor Bordas, que, acompañado al piano por el joven Baldomero Fernández, interpretó de una forma magistral, entre otras piezas, «El Nocturno de Chopín», «La Muñeira» y «Jota de Sarasate», y una «escena de baile de Beriot», las que fueron interrumpidas y finalizadas con nutridas salvas de aplausos.

Todo cuanto pudiéramos decir del joven violinista, sería pálido reflejo de la realidad, pues tenemos que reconocer en el Sr. Bordas, no sólo la portentosa ejecución de Sarasate, sino que también el gusto, sentimiento y delicadeza que caracterizan a Monasterio, cualidades más

40 El Carbayón. Oviedo, VI/939 (11.03.1884). que suficiente para considerarle como un verdadero genio musical.

Terminado el concierto, los dueños de la casa, con la amabilidad y exquisita galantería que siempre les caracterizó, obsequiaron a los concurrentes con pastas, licores y cigarros; y como final de fiesta, se bailó hasta hora bastante avanzada de la noche" ${ }^{41}$.

Junto a este caso detectamos una tímida revitalización de las veladas en el cuartel de Santa Clara, que tanto éxito habían tenido a comienzos de los ochenta, ahora con representaciones dramáticas como plato fuerte y bailes.

Según Fidela Uría, la vida de salón tan prolífica durante la mayor parte del XIX es el germen de las sociedades filarmónicas en Asturias, que verán su aparición en la primera década del siglo XX con la fundación de la Sociedad Filarmónica de Oviedo en $1907^{42}$. Desde entonces convivirán ambas formas de sociabilidad hasta los años se la Guerra Civil, cuando la costumbre de la tertulia desaparece ${ }^{43}$. Con anterioridad a esas fechas ya se echa en falta la actividad en los salones de otros tiempos, como prueba la mención cargada de añoranza que en 1917 Nicomedes Martín-Mateos escribe al recordar las costumbres antaño observadas por ínclitos personajes de la región, tales como el barón de Covadonga:

"El Sr. Valdés Armada estudió la carrera de derecho en la Universidad de Oviedo, en cuya población la morada de sus padres era lo que antes se llamaba un salón, y decimos antes, porque en rigor ha desaparecido casi en todos sitios la vida de sociedad, que añoramos los que, muy progresivos, no tenemos todo lo nuevo por bueno, ni todo lo antiguo por malo y llamado a desaparecer, porque como ha dicho un gran orador, la tradición es vehículo del progreso" 44 .

Como colofón a este trabajo sobre los salones ovetenses, conviene apuntar algunas conclusiones que la revisión del repertorio musical publicado en las crónicas nos ha permitido extraer:

a) El piano y los conjuntos instrumentales de reducidas dimensiones, esencialmente dúos, imperan en las reuniones nocturnas de las clases acomodadas ovetenses, algo natural considerando el tamaño de las dependencias donde se desarrollan. Tras el piano hallamos el violín, aunque mucho más esporádico, que a veces forma dúo con el anterior.

\footnotetext{
41 El Correo de Asturias. II/284 (11.01.1891).

42 URÍA LÍBANO (1997): 64.

43 CASARES RODICIO (1999-2002): 820

44 MARTÍN MATEOS (1916): 118.
} 
Frecuentísima es la combinación de voz y piano, ocasionalmente enriquecida por un grupo coral de pequeño tamaño.

b) El repertorio se compone fundamentalmente de las siguientes obras:

- Transcripciones para piano o violín de fragmentos líricos de ópera o zarzuela (cavatinas, arias, dúos, oberturas, marchas, coros).

- Composiciones instrumentales originales (nocturnos, preludios, estudios, conciertos, sonatas, invenciones, fugas, serenatas, fantasías).

- Danzas, predominantemente foráneas en el caso del piano (valses polcas, mazurcas, galops), y de españolismo característico para el violín (jotas, malagueñas, playeras).

- Canciones y piezas sin especificar, algunas con títulos poéticos, para voz y piano.

- Composiciones religiosas, completas o fragmentadas (Ave María, Salve, Stabat Mater), normalmente interpretadas en reducción para canto y piano.

c) Los autores siguen la tendencia observada en las sociedades musicales: compositores italianos o franceses que en estos años hacen las delicias del público en el ámbito del teatro musical (Rossini, Bellini, Donizetti, Verdi, Mercadante, Gounod, etc.), junto a los clásicos del repertorio camerístico europeo (Beethoven, Schubert, Mendelssohn, Liszt, Bach, Dussek, Cramer, Clementi), y el nombre de algún compositor español, como Sarasate, Monasterio o Zabalza. El repertorio se completa con multitud de obras de compositores que en la actualidad han desaparecido del repertorio, que entonces eran habituales, sobre todo en las interpretaciones de los aficionados, caso de Leybach, Alard, Herold, Vellani, Labarre, Beriot, Corias, Archer, etc.

Se constata, por tanto, la traslación al mundo salonier de la preeminencia alcanzada por los autores italianos más asociados al teatro musical, en convivencia con el repertorio instrumental de cámara, que se hace un hueco en los espacios privados mientras es relegado a un segundo plano en los grandes escenarios, de forma paralela a lo que sucede en las sociedades musicales.

\section{Bibliografía}

Bustillo, Eduardo, "A mi querido amigo Eustaquio Galán, 1857”, en González Solís y Cabal, Protasio, Memorias asturianas. Madrid, Tipografía de Diego Pacheco Latorre, 1890.

Casaprima Collera, Adolfo, Una vida para la música. Historia de la Sociedad Filarmónica de Oviedo. Oviedo, RIDEA, 1993.
Casares Rodicio, Emilio (coord.), Diccionario de la música española e hispanoamericana. Madrid, SGAE, 19992002.

Casielles, Ricardo, "Cuatro entusiastas de la música crearon la Sociedad Filarmónica" (capítulo VIII perteneciente a la serie "La cultura musical de Oviedo"), La Voz de Asturias. Oviedo, 11670 (23.11.1961).

Casielles, Ricardo, "La cultura musical de Oviedo", cap. IX, La Voz de Asturias, 11675 (27.11.1961).

Conde, Ernesto, "Anselmo González del Valle y Carvajal, un artista de la música", El Correo de Asturias. Oviedo (02.09.1988).

Ecos del Nalón. Oviedo, I/5 (15.12.1877).

El Carbayón. Oviedo, III/140 (20.01.1881); V/594 (16.01.1883);V/607(01.02.1883);V/610 (07.02.1883); VI/939 (11.03.1884); VI/979 (29.04.1884); VI/1140 (26.11.1884); $\quad$ VII/1182 (05.01.1885); $\quad$ VII/1200 (26.01.1885); $\quad$ VII/1217 (16.02.1885); $\quad$ VII/1224 (24.02.1885); $\quad$ VII/1252 (30.03.1885); $\quad$ VII/1295 (21.05.1885); $\quad$ VII/1353 (31.07.1885); $\quad$ VII/1405 (01.10.1885); VII/1407 (05.10.1885); y $\mathrm{IX} / 1816$ (23.02.1887).

El Correo de Asturias. II/284 (11.01.1891).

El Occidente de Asturias. Cangas de Tineo, V/ 354 (15.01.1886).

Fernández García, Antonio, "La sociedad de fin de siglo en La Regenta", Homenaje a D. José Luis Comellas. Sevilla, Universidad de Sevilla, 2000.

García de Castro, Ramón, "Aquellos tiempos del Carbayón...”, La Nueva España. Oviedo (26.08.1979).

García Miñor, Antonio, "Las tertulias de ayer", La Voz de Asturias (18.07.1976).

García Miñor, Antonio, "Baldomero Fernández Casielles o el infortunio", La Voz de Asturias, Oviedo (26.03.1978).

González Solís y Cabal, Protasio, Memorias asturianas. Madrid, Tipografía de Diego Pacheco Latorre, 1889.

Martín Mateos, Nicomedes, Biografías asturianas. Madrid, Imp. Part. de "Patria y Letras", 1916.

Martínez García, Gabriel, Dos vidas paralelas: Baldomero Fernández y Manuel del Fresno (notas para la historia de dos frustraciones ovetenses). Oviedo, IDEA, 1975.

Revista de Asturias. Oviedo, II/36 (25.10.1878).

Señas Encinas, Fernando, "Cuando Oviedo era redondo", Revista San Mateo. Oviedo, Espacio Publicaciones, 1949.

Señas Encinas, Fernando, "El Oviedo de Palacio Valdés", Boletín del Instituto de Estudios Asturianos. Oviedo, IDEA, 1953.

Uría Líbano, Fidela, “Asturias y la música de cámara”, Cambio de tercio. Música española para cuarteto de cuerda. Oviedo, Caja de Asturias, 1995. 
Uría Líbano, Fidela, Historia de la música asturiana entre 1869 y 1934. Oviedo, Consejería de Cultura, 1997.

Uría Líbano, Fidela, Música asturiana entre 1860-1934: vida, obra y catálogo de Víctor Sáenz, Anselmo Gon- zález del Valle, Baldomero Fernández. Oviedo, Servicio de Publicaciones del Principado de Asturias, 1997.

Recibido: 10.10 .2011

Aceptado: 02.11.2015 